\title{
INDICAPS II: A Bird's Eye View of the Indian Intensive Care Landscape
}

\author{
Raj K Mani॰
}

Keywords: End-of-life care, ICU management, ICU mortality, Indian intensive care unit, Intensive care, Left against medical advice. Indian Journal of Critical Care Medicine (2021): 10.5005/jp-journals-10071-24003

Across the diversity of India, critical care access, though grossly insufficient and uneven, has been increasing. A 1-day point prevalence survey of the case mix and the practice patterns was first conducted in the INDICAP study across 120 adult ICUs from 2010 to 2011 . $^{1}$ Ten years on, the investigators have repeated the exercise across a larger number of ICUs. In this issue of IJCCM, the findings of a 4-day point prevalence study, the INDICAPS II, reflecting contemporary Indian critical care practice, are published. ${ }^{2}$ The data were collected during 2018-2019 from 132 ICUs and 4,669 patients. INDICAPS I and INDICAPS II are not strictly comparable-in the time interval, ICU practice has changed considerably; the participating ICUs were different; the criteria for adequacy of an ICU had changed, and INDICAPS II had fewer ICUs classified as adequately equipped (47 vs $67.5 \%$ ). Most ICUs included in this study were not NABH/JCI Accredited. The vast majority of ICUs was from the private sector (95.6\%).

A point prevalence study attempts to present the observational data on a single moment in time in order to explore the real-life scenario. Such a design may have inherent biases-how selected, whether enrolment was voluntary or otherwise, seasonal variation in the case mix, and whether the data were independently monitored or not. INDICAPS II was based on unverified data provided by participant units voluntarily enrolled. Despite these reservations, the study provides interesting information across the subcontinent on multiple aspects of day-to-day critical care.

INDICAPS II had a staggered point prevalence design, i.e., data were collected on four different days of four different months to control for seasonal variation of disease prevalence.

The study had similar age of the population as compared to the much larger international point prevalence study on ICU infections ${ }^{3}$ (60.7 vs 56.7 years) and similar prevalence of infection and sepsis (51 vs $54.9 \%$ ) in the overall study population. In INDICAPS II, the new definition of sepsis of SOFA score $>2$ was incorporated. The average APACHE II and SOFA scores reflect a moderate severity of illness. Nearly a quarter of the patients were mechanically ventilated and a fifth were on vasopressors and inotropes. The overall Mean ICU and hospital days were 6 and 12. The nonsurvivors had a significantly more prolonged stay of 9 days reflecting potentially higher cost of medical treatment in this group. There were fewer self-paying patients in INDICAPS II compared to INDICAPS I (64.5 vs $80.5 \%$ ). The outof-pocket expenses on in-patient decedents were found to be unbearable for the majority of families in the large National Sample Survey. ${ }^{4}$ The costs of ICU care were not explored further in this study.
Department of Critical Care and Pulmonology, Yashoda Super Speciality Hospitals, Ghaziabad, Uttar Pradesh, India

Corresponding Author: Raj K Mani, Department of Critical Care and Pulmonology, Yashoda Super Speciality Hospitals, Ghaziabad, Uttar Pradesh, India, Phone: +919811131719, e-mail: raj.rkmjs@gmail.com

How to cite this article: Mani RK. INDICAPS II: A Bird's Eye View of the Indian Intensive Care Landscape. Indian J Crit Care Med 2021; 25(10):1087-1088.

Source of support: Nil

Conflict of interest: None

The primary outcome measure was the 30-day ICU mortality of 1,092 out of 4,669 patients (25.3\%). Almost a third of this included terminal discharges (TDs) classified as deaths, which were more than that in INDICAPS I (7.6 vs 4.5\%). Such discharges are generally mediated through the so-called left against medical advice/ discharged against medical advice (LAMA/DAMA) designation. As mentioned elsewhere, ${ }^{5}$ this is an ethically unjustifiable practice that represents unplanned treatment limitations without a formal shift to palliative care. In this study, the TDs have been rightly classified as mortality so as not to undercount the deaths, but as the authors admit, this could have somewhat overestimated the rate.

The study does not mention the rate of compliance with formal end-of-life care (EoLC) practices as outlined in the ISCCMIAPC guideline $2014 .{ }^{6}$ TDs remain high as in INDICAPS I, and formal withdrawal/withholding of life support (WD/WH) was either not done or was concealed. This is contrary to the current practices in the world, where decisions to limit treatment are made in $90 \%$ of ICU deaths. ${ }^{7}$ The authors mention the physicians' perceived legal obstacles in the wake of the Aruna Shanbaug judgment ${ }^{8}$ that required a court procedure for WD/WH decisions in India. Physician confidence could improve with the March 2018 Supreme Court Judgment, the Common Cause vs Union of India ${ }^{9}$ that established unequivocally, the constitutionality of treatment refusal, Advance Medical Directive (AMD), and WD/WH. However, the procedures for both AMD execution and implementation of $\mathrm{WD} / \mathrm{WH}$ remain complicated for which vigorous advocacy is on for improving its applicability. ${ }^{10}$

A surprising finding in the survey is that closed ICUs were associated with a higher standardized mortality ratio. This counterintuitive finding deserves a closer scrutiny. The criterion of a closed ICU defined in this study is somewhat simplistic. The authority to write the final treatment orders alone may not reflect

(c) The Author(s). 2021 Open Access This article is distributed under the terms of the Creative Commons Attribution 4.0 International License (https://creativecommons org/licenses/by-nc/4.0/), which permits unrestricted use, distribution, and non-commercial reproduction in any medium, provided you give appropriate credit to the original author(s) and the source, provide a link to the Creative Commons license, and indicate if changes were made. The Creative Commons Public Domain Dedication waiver (http://creativecommons.org/publicdomain/zero/1.0/) applies to the data made available in this article, unless otherwise stated. 
the total ownership of the patient's care by a single-personled critical care team. Open ICUs with mandatory intensivist consultation ("hybrid") are clubbed together with truly open ICUs where the management plan is by individual consultants admitting a case. An overwhelming majority of ICUs is thus hybrid or open. Evidently, several important variables impacting outcome may be hidden; the truly closed ICUs may be far fewer than estimated in this study, and thus, no reliable conclusions can be drawn. In the world, the closed vs open controversy still rages. While Pronovost et al. ${ }^{11}$ and the meta-analysis by Wilcox et al. ${ }^{12}$ demonstrated superiority of the closed model, Levy et al. ${ }^{13}$ concluded the opposite. In the latter survey, the ventilator management was by trained respiratory therapists and critical care medicine-trained resident and nursing staff were available round-the-clock. In North America, the UK, Western Europe, and Oceania, the majority of ICUs are closed units. ${ }^{14}$ It is pertinent to mention that in Australia and New Zealand where the most complete model of closed ICU exists (training and certification, complete handover to the critical care team), the mortality figures are more favorable than elsewhere. ${ }^{14}$ There are several important goals such as team culture and cohesion, effective communication, family satisfaction, and fostering of an ethical environment that are better accomplished in a closed unit. These aspects are, of course, less easily measurable. The strengths of the open and hybrid models are possibly a greater collaboration between the ICU staff and noncritical care physicians and a continuity of care before and after ICU stay. In India, this advantage can be offset by the inevitability of too many decision-makers coming in the way of each other.

As expected, the majority of ICUs have a nurse: patient ratio $<1: 2$. Contrary to the EPIC II study, the ratio of $<1: 2$ vs $>1: 2$ did not impact outcome. Possibly, there are hidden confounders such as the quality of training of the nursing staff and the availability of critical care residents/consultants on-site.

At 35\%, ICU mortality in the subset of sepsis remains high. The microbial pattern of infections shows a predominance of gramnegative bacteria (75\%) and only $13.6 \%$ of gram-positive bacteria and fungi $9.7 \%$, unlike the EPIC II data showing much higher proportions of the latter two. ${ }^{7}$ By common practice experience and by EPIC II data, we also know of increasing Acinetobacter baumannii infections in low- and middle-income countries. The prevalence separately of Acinetobacter spp., extended-spectrum beta-lactamase (ESBL)producing and carbapenemase- and metalloproteinase-producing bacteria is not mentioned in this study. Surprisingly, the collective proportion of mycobacteria, dengue, H1N1 influenza, scrub typhus, HIV, malaria, and leptospirosis is small (5.3\%). Notably, $16.5 \%$ received more than three antimicrobials. Among the quality assessments, we do not find antibiotic stewardship policies and implementation or the rate of compliance with $\mathrm{NABH}$ guidelines on EoLC. A reasonably good compliance of mechanical ventilation guidelines exists. The compliance for pain and sedation assessment is moderate but low for delirium. Overall, the latter reflects a low awareness for and integration of palliative care principles in Indian ICUs. Inappropriate triggers for transfusion were significant at (7.7-25.3\%) that call for stricter quality control.

The estimated number of private and public ICU beds in India is 94,961 , out of which 35,699 are public and 59,262 private. ${ }^{15}$ The INDICAPS II findings that have thus included data from only $5 \%$ of ICU beds with a minuscule contribution from public hospitals may not be generalizable to the entire critical care landscape of India. Attention to surgical patients is also inadequate as $95.5 \%$ of the study population were medical admissions. Further, rural India that comprises $72 \%$ of the population has access only to $28 \%$ of the hospital beds. In this study, only 68 (1.5\%) of ICU admissions were of poisonings and snakebites were merely 4 in number, clearly pointing to missing rural data. These uncertainties should lead to further refinements in design and more inclusivity in participation for a replication of this laudable effort in the future.

\section{OrCID}

Raj KMani $\odot$ https://orcid.org/0000-0003-4759-8233

\section{References}

1. Divatia JV, Amin PR, Ramakrishnan N, Kapadia FN, Todi S, Sahu S, et al. Intensive care in India: the Indian intensive care case mix and practice patterns study. Indian J Crit Care Med 2016;20(4):216-225. DOI: $10.4103 / 0972-5229.180042$.

2. Divatia JV, Mehta Y, Govil D, Zirpe K, Amin PR, Ramakrishnan N, et al. Intensive Care in India in 2018-2019: The Second Indian Intensive Care Case Mix and Practice Patterns Study. Indian J Crit Care Med 2021;25(10):1091-1105.

3. Vincent J, Rello J, Marshall J, Silva E, Anzueto A, Martin CD, et al. International study of the prevalence and outcomes of infection in intensive care units. JAMA 2009;302(21):2323-2329. DOI: 10.1001/ jama.2009.1754.

4. Das SK, Ladusingh L. Why is the inpatient cost of dying increasing in India? PLoS One 2018;13(9):e0203454. DOI: 10.1371/journal. pone.0203454.

5. Mani RK. End-of-life care in India. Intensive Care Med 2006;32(7): 1066-1068. DOI: 10.1007/s00134-006-0185-7.

6. Myatra SN, Salins N, lyer S, Macaden SC, Divatia JV, Muckaden M, et al. End-of-life care policy: an integrated care plan for the dying. Indian J Crit Care Med 2014;18(9):615-635. DOI: 10.4103/0972-5229.140155.

7. Sprung CL, Ricou B, Hartog CS, Maia P, Mentzelopoulos SD, Weiss $M$, et al. Changes in end-of-life practices in European intensive care units from 1999-2016. JAMA 2019;322(17):1692-1704. DOI: 10.1001/ jama.2019.14608.

8. Aruna Ramachandra Shanbaug vs. The Union of India \& Ors. writ petition (Criminal) No. 115 of 2009(Supreme Court of India Proceedings).

9. Reportable in: The Supreme Court of India Civil Original Jurisdiction. Common cause vs The Union of India. Writ Petition (Civil) no. 215 of 2005.

10. Vidhi Centre for Legal Policy and End of Life Care in India Task Force, End of Life Care in India. A model legal framework. 2019. Available from: https://vidhilegalpolicy.in/wp-content/ uploads/2019/11/191031_-End-of-Life-Care-in-India-A-Model-LegalFramework.pdf.

11. Pronovost PJ, Angus DC, Dorman T, Robinson KA, Dremsizov TT, Young TL. Physician staffing patterns and clinical outcomes in critically ill patients: a systematic review. JAMA 2002;288(17):21512162. DOI: 10.1001/jama.288.17.2151.

12. Wilcox ME, Chong CA, Niven DJ, Rubenfeld GD, Rowan KM, Wunsch $\mathrm{H}$, et al. Do intensivist staffing patterns influence hospital mortality following ICU admission? A systematic review and meta-analyses. Crit Care Med 2013;41(10):2253-2274. DOI: 10.1097/ CCM.0b013e318292313a.

13. Levy MM, Rapoport J, Lemeshow S, Chalfin DB, Phillips G, Danis M. Association between critical care physician management and patient mortality in the intensive care unit. Ann Intern Med 2008;148(11): 801-809. DOI: 10.7326/0003-4819-148-11-200806030-00002.

14. Deane AM. Intensivists under threat: who's in charge here? Crit Care Resusc 2014;16(2):138-139. Available from: https://search.informit. org/doi/10.3316/informit.312838771059785.

15. Estimated number of public and private ICU beds in India. 2019 Available from: https://www.statista.com/statistics. 